\title{
STRATEGI PEMASARAN AGROINDUSTRI SEBAGAI UPAYA MENDUKUNG INVESTASI DAERAH DI PROVINSI KALIMANTAN TIMUR
}

\section{(AGROINDUSTRY MARKETING STRATEGY AS AN EFFORTS TO SUPPORT REGIONAL INVESTMENTS IN EAST KALIMANTAN PROVINCE)}

\author{
Zhikry Fitrian, Eka Nor Santi, Fajar Febrian Putranto \\ Badan Penelitian dan Pengembangan Daerah Provinsi Kalimantan Timur \\ Jl. MT. Haryono No. 126 Samarinda \\ Email: zicree@gmail.com
}

Diterima: 19 Juni 2019; Direvisi: 5 Juli 2019; Disetujui: 8 Juli 2019

\begin{abstract}
ABSTRAK
Pemerintah Provinsi Kalimantan Timur melalui Visi Kaltim Maju 2018, yakni Mewujudkan Kaltim Sejahtera yang Merata dan Berkeadilan Berbasis Agroindustri dan Energi Ramah Lingkungan, berupaya untuk mengubah perekonomiannya yang semula berdasarkan pada unrenewable resources menjadi renewable resources berbasis agroindustri. Walaupun agroindustri menjadi visi utama Provinsi Kalimantan Timur namun dalam kurun waktu 2014-2017 peningkatan PDRB dari Sektor Pertanian hanya terjadi di bawah angka $1 \%$. Artikel ini bertujuan untuk menganalisis investasi di sektor agroindustri di provinsi Kalimantan Timur dalam pemasaran daerah. Pasca desentralisasi, pemerintah daerah harus dapat menarik investasi di daerah. Khususnya, Provinsi Kalimantan Timur yang memiliki visi untuk menjadi provinsi agroindustri, memerlukan kiat-kiat khusus bagi investor yang mau menanamkan modalnya di Kalimantan Timur pada sektor agroindustri. Analisis yang digunakan adalah segmentasi pasar, analisis SWOT, diferensiasi dan bauran pemasaran. Hasil dari artikel ini adalah bahwa pasar membutuhkan konsistensi dan kerja keras oleh para pemangku kepentingan. Semua aspek potensi pemasaran daerah harus dioptimalkan penggunaannya karena mereka tidak bisa berdiri sendiri. Daerah tidak bisa hanya mengandalkan keuangannya sendiri untuk mengembangkan daerahnya. Upaya daerah harus memiliki kreatif dan inovatif dalam memenuhi peluang bisnis di daerah. Tren persaingan antardaerah dalam menarik investasi, terutama di sektor agroindustri di provinsi Kalimantan Timur perlu didukung dengan data dan potensi pengembangan strategi masing-masing daerah.
\end{abstract}

Kata kunci: Pemasaran Daerah, Agroindustri, Investasi, Kalimantan Timur

\begin{abstract}
The East Kalimantan Provincial Government through the East Kalimantan Vision 2018, namely To Realize a Equitable and Fair Prosperous East Kalimantan Based on Agroindustry and Environmentally Friendly Energy, strives to change its economy which was originally based on unrenewable resources into agroindustry-based renewable resources. Although agroindustry is the main vision of East Kalimantan Province, in the period of 2014-2017 the increase in GDRP from the Agriculture Sector only occurred below 1\%. This article aims to analyze the investment in agroindustry sector in the province of East Kalimantan in the regional marketing. Post decentralization, local governments should be able to attract investment in the region. Specially, Eastern Kalimantan Province that has a vision to become the province of agroindustry, required special tips for investors willing to invest their capital in East Kalimantan on the agroindustry sector. The analysis used is market segmentation, SWOT analysis, differentiation and marketing mix. The results of this article is that the market takes consistency and hard work by the stakeholders. All aspects of the marketing potential of the region should be optimized usage because they can not stand on their own. Regions can not simply rely on its own finances to develop their
\end{abstract}


regions. Regional efforts should have a creative and innovative in meeting the business opportunities in the area. The trend in interregional competition in attracting investment, especially in the agroindustry sector in the province of East Kalimantan needs to be supported with data and strategy development potential of each region.

Keywords: Regional Marketing, Agroindustry, Investment, East Kalimantan.

\section{PENDAHULUAN}

Pembangunan ekonomi Indonesia sekarang dan masa depan seharusnya mengarah kepada era liberalisasi perdagangan yang ditandai oleh adanya perubahan term of trade sehingga perdagangan lambat laun akan kehilangan subsidi dan tarif. Sebaliknya, arus laju lintas modal antarnegara semakin meningkat sehingga menimbulkan foreign direct investment (Devaragan, Lewis dan Robinson, 1990).

Berdasarkan kondisi tersebut, kinerja industri di Indonesia cepat atau lambat akan dihadapkan pada situasi dan kondisi dimana industri yang mendapat perlindungan dari pemerintah melalui subsidi atau tarif akan tertekan pada posisi yang tidak diuntungkan. Kemudian industri yang padat modal dan tergolong industri berat yang tingkat keunggulan komparatifnya rendah akan dihadapkan pada tantangan produk-produk impor ataupun produk dari investasi asing secara langsung. Selanjutnya industri monopoli akan dipaksa bersifat kompetitif karena tekanan produk impor. Sedangkan industri padat modal dan teknologi dihadapkan pada ketidakpatuhan konsumen dalam mengkonsumsi produk industri yang bersangkutan karena cepatnya arus informasi menyebabkan biaya pemasaran tidak efisien. Namun untuk industri yang berbasis sumber daya lokal akan berada dalam posisi yang relatif aman dalam era liberalisasi perdagangan.

Kondisi tersebut hanya dapat diatasi melalui dua cara, yaitu mewujudkan efisiensi dalam proses produksi dan memprioritaskan pengembangan agroindustri yang berbasis sumber daya lokal, bersinergi, dan terintegrasi. Oleh karena itu, strategi pembangunan nasional harus menempatkan agroindustri sebagai pilihan utama yang tidak dapat ditawar lagi karena agroindustri akan memicu percepatan peningkatan kesempatan kerja, peningkatan ekspor, pertumbuhan ekonomi, pemerataan pendapatan, pengentasan kemiskinan, dan jaminan ketahanan nasional. Dengan demikian, agroindustri seharusnya dipandang sebagai salah satu sumber pertumbuhan ekonomi utama dan terdepan di Indonesia. Strategi menurut Quinn (1980) adalah suatu pola atau perencanaan yang mampu mengintegrasikan sasaran, kebijakan, dan tindakan-tindakan organisasi secara kohesif. Menurut Kotler (2002), pemasaran merupakan proses sosial dan manajerial yang dilakukan oleh individual maupun kelompok dalam rangka memenuhi kebutuhan dan keinginan melalui suatu proses penciptaan dan pertukaran produk dan nilai dengan pihak lain. Jadi, hakekat utama proses pemasaran adalah upaya penciptaan kepuasan konsumen oleh produsen melalui penciptaan dan pertukaran sesuatu. Agroindustri adalah perusahaan yang mengolah bahan yang berasal dari tumbuhan dan hewan. Pengolahan meliputi transformasi dan pengawetan melalui perubahan fisik atau kimia, penyimpanan, pengepakan, dan distribusi. Dengan demikian, pengembangan agroindustri adalah suatu pola atau perencanaan usaha yang mampu mengintegrasikan sasaran dan kebijakan ke arah yang lebih baik guna mendapatkan nilai tambah komoditi yang sebesar-besarnya.

Terdapat empat kekuatan strategi agroindustri menurut Austin (1992) yang dapat dijadikan motor penggerak perekonomian suatu negara. Pertama, agroindustri merupakan pintu keluar bagi produk pertanian, artinya produk pertanian memerlukan pengolahan sampai tingkat tertentu sehingga meningkatkan nilai tambah. Kedua, agroindustri merupakan penunjang utama sektor manufaktur, artinya sumber daya pertanian sangat diperlukan pada tahap awal industrialisasi dan agroindustri serta mempunyai kapasitas yang besar dalam menciptakan lapangan kerja, meningkatkan produksi, dan pemasaran, serta mengembangkan lembaga keuangan dan jasa. Ketiga, agroindustri berperan dalam menciptakan devisa negara, artinya 
produk pertanian mempunyai permintaan di pasar dunia baik dalam bentuk bahan baku, setengah jadi, maupun produk jadi sehingga perlu pengolahan sesuai dengan permintaan konsumen. Keempat, agroindustri mempunyai dimensi nutrisi, artinya agroindustrj dapat menjadi pemasok kebutuhan gizi masyarakat dan pemenuhan kebutuhan pangan nasional.

Provinsi Kalimantan Timur menangkap peluang ini, melalui Visi Kaltim Maju 2018, yakni "Mewujudkan Kaltim Sejahtera yang Merata dan Berkeadilan Berbasis Agroindustri dan Energi Ramah Lingkungan", Kalimantan Timur berupaya untuk mengubah perekonomiannya yang semula berdasarkan pada unrenewable resources menjadi renewable resources berbasis agroindustri. Hal ini penting untuk dilakukan mengingat sumbangan Sektor Pertanian pada tahun 2014 sebesar Rp. 36,95 triliun atau 7 \% dari total PDRB Kaltim tahun 2014 sebesar Rp. 527,15 Triliun dan pada tahun 2017 Sektor Pertanian menyumbang sebesar Rp. 47,14 Triliun atau 7,96\% dari total PDRB Kaltim tahun 2017 sebesar Rp. 592,5 Triliun seperti pada grafik dibawah ini (BPS Kaltim, 2018). Angka tersebut menunjukkan bahwa walaupun agroindustri menjadi visi utama Provinsi Kalimantan Timur namun dalam waktu 3 tahun hanya terjadi peningkatan PDRB dari Sektor Pertanian di bawah angka $1 \%$.

Mengingat kecilnya sumbangan PDRB sektor pertanian terhadap total PDRB di Provinsi Kalimantan Timur maka diperlukan suatu upaya untuk meningkatkan sumbangan sektor tersebut terhadap PDRB Kaltim salah satunya melalui agroindustri. Untuk mengubah basis perekonomian ini tidak mudah. Diperlukan sumber daya yang besar dalam aspek finansial. Aspek finansial ini dapat diperoleh melalui investasi baik dari pihak pemerintah maupun pihak swasta baik dari dalam maupun luar negeri.

Untuk dapat memperoleh investasi yang besar maka diperlukan upaya untuk memasarkan Kalimantan Timur sebagai pusat Agroindustri di Indonesia. Upaya-upaya tersebut dilakukan oleh Pemerintah Provinsi Kalimantan Timur dengan membuat dua mega proyek yaitu Food Estate Delta Kayan dan Pelabuhan Kawasan Industri dan Pelabuhan Internasional (KIPI) Maloy.

Dalam pelaksanaannya memasarkan daerah di Indonesia bukanlah perkara mudah. Persoalan utama yang biasa dihadapi adalah mengenai pola pikir para penyelenggara pemerintah daerah. Selama ini, para penyelenggara pemerintah memiliki cara berpikir birokratif. Pola pikir ini harus diubah menjadi pola pemasaran yang berorientasi konsumen. Hal ini berarti aparat pemerintah harus berupaya untuk memenuhi kebutuhan pelanggannya (dalam hal ini investor agroindustri). Prosedur birokrasi yang panjang harus dipangkas bahkan ditinggalkan. Sistem infrastruktur yang ada dalam pemerintahan harus dibenahi agar lebih efektif dan efisien. Untuk itu, artikel ini bertujuan untuk menganalisis strategi pemasaran agroindustri dan pengaruh pemasaran daerah terhadap investasi di Provinsi Kalimantan Timur disamping itu juga manganalisis positioning daerah dalam upaya memasarkan daerah dan mendukung investasi daerah.

\section{METODE}

Strategi Pemasaran Agroindustri Sebagai Upaya Mendukung Investasi Daerah di Provinsi Kalimantan Timur ini dilakukan dengan metode deskriptif melalui studi pustaka (desk study). Studi pustaka dilakukan dengan mencari literatur serta peraturan atau perundang-undangan yang terkait dengan strategi pemasaran dan peningkatan investasi daerah. Selain itu, studi pustaka juga dilakukan dalam mencari informasi terkait kondisi dan perkembangan agroindustri di Kalimantan Timur. Informasi dan data yang diperoleh dari studi pustaka terkait strategi pemasaran dan agroindustri tersebut kemudian dianalisis menggunakan metode SWOT (Strengths, Weaknesses, Opportunities and Threats) untuk mengidentifikasi peluang, ancaman, kekuatan dan kelemahan daerah. Berdasarkan hasil analisis tersebut, kemudian disusun strategi pemasaran melalui penentuan segmentasi dan targeting daerah. Strategi yang disusun tersebut 
kemudian dilanjutkan dengan menetapkan strategi pemasaran dalam bentuk diferensiasi dan bauran pemasaran.

\section{HASIL DAN PEMBAHASAN}

Secara umum memasarkan daerah berarti mendesain suatu daerah agar mampu memenuhi dan memuaskan keinginan dan ekspektasi target marketnya (Kartajaya dan Yuswohadi, 2005). Agar sebuah strategi sebuah daerah berjalan dinamis maka harus dilakukan analisis lingkungan daerah. Aspek yang dilihat adalah lingkungan internal dan eksternal (SWOT analysis). Analisis internal meliputi Kekuatan (Strenght) dan Kelemahan (Weakness) daerah dan analisis eksternal meliputi Peluang (Opprtunity) dan Ancaman (Threat). Adapun analisis SWOT mengenai agroindustri di Kalimantan Timur seperti pada Tabel 1.

Tabel 1. Analisis SWOT Sektor Agroindustri di Kalimantan Timur

\begin{tabular}{|c|c|c|}
\hline & Kekuatan & Kelemahan \\
\hline Analisis Internal & $\begin{array}{l}\text { 1. Dukungan fasilitas dari APBD } \\
\text { 2. Termasuk satu diantara } 3 \text { (tiga) } \\
\text { skala prioritas pembangunan di } \\
\text { Kaltim } \\
\text { 3. Posisi geografis Kaltim yang } \\
\text { strategis } \\
\text { 4. Ketersediaan Sarana Produksi } \\
\text { dan Permodalan } \\
\text { 5. Tersedianya potensi sumber } \\
\text { daya lahan yang cukup besar } \\
\text { 6. Iklim usaha yang kondusif } \\
\text { 7. Terletak pada selat Makassar } \\
\text { (ALKI II) sebagai jalur } \\
\text { perdagangan } \\
\text { 8. Kondisi keamanan yang stabil }\end{array}$ & $\begin{array}{l}\text { 1. Beralihnya fungsi kawasan } \\
\text { pertanian menjadi kawasan } \\
\text { pemukiman dan industri } \\
\text { 2. Kualitas dan kuantitas SDM } \\
\text { Agroindustri yang masih rendah } \\
\text { 3. Ekonomi biaya tinggi, } \\
\text { 4. Hambatan Logistik dan } \\
\text { Infrastruktur } \\
\text { 5. Hambatan } \\
\text { Teknologi }\end{array}$ \\
\hline Analisis Eksternal & $\begin{array}{l}\text { Peluang } \\
\text { 1. Peluang pasar dalam dan luar } \\
\text { daerah/negeri yang cukup } \\
\text { besar. } \\
\text { 2. Dukungan APBN } \\
\text { 3. Masih banyaknya potensi } \\
\text { agroindustri di Kaltim yang } \\
\text { belum tereksplorasi. } \\
\text { 4. Otonomi daerah memberikan } \\
\text { kesempatan kepada Pemda } \\
\text { untuk dapat menarik investasi } \\
\text { ke Kaltim secara maksimal }\end{array}$ & $\begin{array}{l}\text { Ancaman } \\
\text { 1. Pangan merupakan pemicu } \\
\text { instabilitas politik dan ekonomi } \\
\text { bila terjadi kekurangan produksi. } \\
\text { 2. Harga komoditi agroindustri dari } \\
\text { luar daerah/negeri lebih murah } \\
\text { 3. Pengaruh faktor alam terhadap } \\
\text { kegiatan produksi tidak dapat } \\
\text { dikendalikan } \\
\text { 4. Adanya organisasi perdagangan } \\
\text { dunia (WTO), liberalisasi } \\
\text { perdagangan dan investasi } \\
\text { dalam APEC, serta skema CEPT } \\
\text { dalam AFTA-ASEAN, maka gerak } \\
\text { perdagangan dunia semakin } \\
\text { dinamis dan cepat. } \\
\text { 5. Kerusakan lingkungan. }\end{array}$ \\
\hline
\end{tabular}

Sumber : Hasil Analisis (2018)

Hasil analisis kondisi internal dan eksternal sektor agroindustri di Kalimantan Timur dengang menggunakan SWOT kemudian dijadikan dasar dalam perumusan strategi pemasaran. Tahap pertama yaitu dengan melakukan segmentasi, yaitu membagi sebuah pasar ke dalam 
kelompok-kelompok pembeli yang khas berdasarkan kebutuhan, karakteristik atau perilaku yang mungkin membutuhkan produk atau bauran pemasaran yang terpisah. Segmen pasar terdiri dari kelompok pelanggan yang memiliki seperangkat keinginan yang sama (Kotler, 2003). Kartajaya dan Yuswohady (2005) menyatakan ada tiga syarat yang harus dipenuhi sebagai acuan dalam penentuan diferensiasi, yaitu:

1. Diferensiasi haruslah mampu mendatangkan nilai dan manfaat excelent kepada investor. Produk atau layanan daerah boleh berbeda, tapi tentu tidak boleh asal beda. Perbedaan tersebut harus mampu mendatangkan nilai dan manfaat yang excellent kepada investor. Semakin perbedaan tersebut mendatangkan manfaat yang tinggi, semakin kokoh pula diferensiasi yang dihasilkan

2. Diferensiasi merupakan keunggulan dibanding pesaing. Sebuah diferensiasi akan kokoh jika Anda menciptakan perbedaan dengan pesaing dan perbedaan tersebut mencerminkan keunggulan Anda terhadap pesaing. Diferensiasi akan kokoh jika Anda mampu keluar dari paritas pesaing alias berada di atas rata-rata pencapaian pesaing umum.

3. Agar diferensiasi daerah kokoh dan sustainable, ia harus memiliki keunikan sehingga tak gampang dikopi pesaing.

Adapun pembagian segmentasi investor agroindustri di Kalimantan Timur seperti Gambar 1.

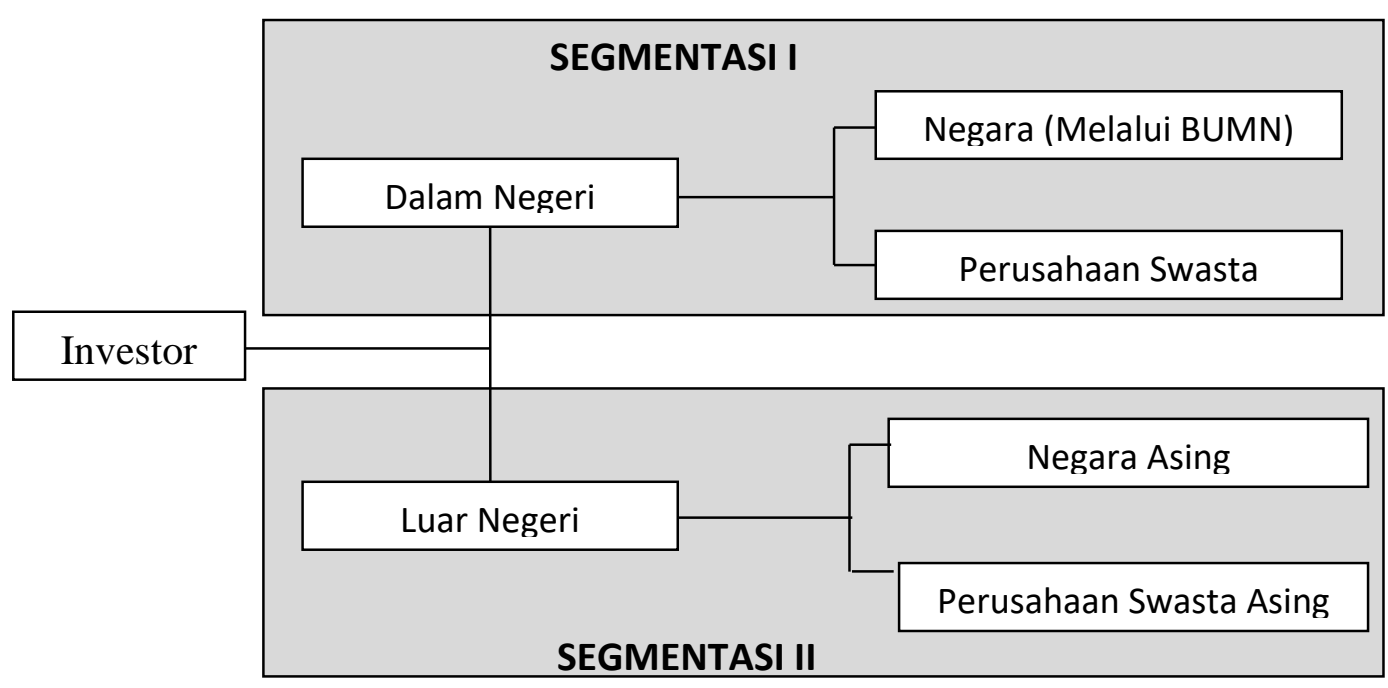

Gambar 1. Segementasi Investor Agroindustri di Provinsi Kalimantan Timur Sumber : Hasil Analisis (2018)

Setelah dilakukan segmentasi, maka proses selanjutnya dalah melakukan targeting. Targeting adalah mengalokasikan sumberdaya daerah secara efektif melalui pemilihan target pasar yang tepat. Dalam usaha menjadikan Provinsi Kalimantan Timur sebagai Provinsi Agroindustri, ada dua mega proyek yang akan dikembangkan yaitu Pelabuhan Kawasan Industri dan Pelabuhan Internasional (KIPI) Maloy dan pengembangan Rice Food Estate Delta Kayan (saat ini masuk wilayah Kalimantan Utara). Seperti yang ditampilkan pada Tabel 2, Segmentasi I dilakukan untuk Proyek Food Estate Delta Kayan karena nilai proyek relatif lebih kecil daripada Proyek Pelabuhan KIPI Maloy. Selain itu dikarenakan proyek food estate berkaitan dengan sektor pangan, sehingga dianggap terlalu berisiko bila masuk pada Segmentasi II.

Tabel 2. Targeting Investor Agroindustri di Provinsi Kalimantan Timur

$\begin{array}{lll}\text { Proyek Segmentasi Investor } & \end{array}$


Strategi Pemasaran Agroindustri Sebagai Upaya Mendukung Investasi Daerah di Provinsi Kalimantan Timur Zhikry Fitrian, Eka Nor Santi dan Fajar Febrian Putranto

\begin{tabular}{lll}
\hline Food Estate Delta Kayan & Segmentasi I & $\begin{array}{l}\text { Badan Usaha Milik Negara (BUMN) dan Perusahaan } \\
\text { Swasta dalam negeri }\end{array}$ \\
& Segmentasi II & Negara Asing dan Perusahaan Swasta Asing \\
\hline Pelabuhan KIPI Maloy & &
\end{tabular}

Tahap berikutnya dalam menentukan strategi pemasaran agroindustri di Kalimantan Timur adalah dengan melakukan diferensiasi dan bauran pemasaran. Menurut Kotler (2002), definisi pembedaan atau diferensiasi (differentiation) adalah tindakan untuk menetapkan sekumpulan perbedaan-perbedaan yang berarti untuk membedakan penawaran perusahaan dari persaingannya. Dalam konteks daerah, diferensiasi adalah upaya membedakan diri dengan daerah pesaing baik dalam hal konten, konteks dan infrastruktur. Produk dan layanan daerah dirancang agar unik dan berbeda dari produk dan layanan daerah pesaing. Upaya merancang keunikan dan perbedaan ini bisa berdasarkan konten atau apa yang ditawarkan kepada investor (what to offer) dan bagaimana cara daerah menawarkannya (how to offer). Dua kawasan pengembangan agroindustri di Kalimantan Timur adalah Pelabuhan Kawasan Industri dan Pelabuhan Internasional (KIPI) Maloy dan pengembangan Rice Food Estate Delta Kayan. Untuk menarik investasi pada agroindustri di daerah tersebut, maka Pemerintah Provinsi Kalimantan Timur dapat melakukan sesuatu yang membedakan dengan daerah lain yaitu seperti Tabel 3.

Tabel 3. Diferensiasi Yang Ditawarkan Kepada Investor di Provinsi Kalimantan Timur

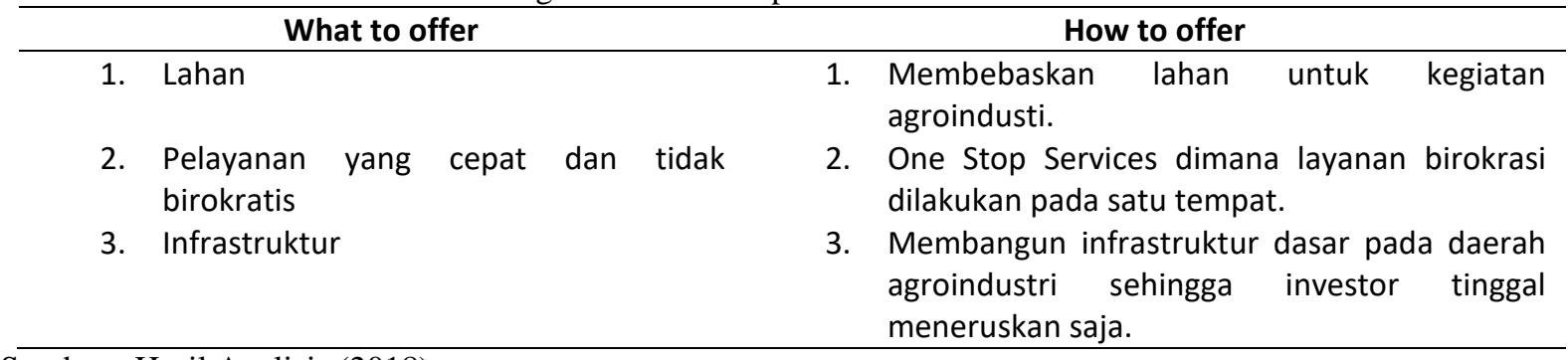

Sumber : Hasil Analisis (2018)

Bauran pemasaran terdiri atas empat variabel pokok yaitu : (1) product, (2) price, (3) place, (4) promotion. Penerapan strategi bauran pemasaran tidak terlepas dari sistem lingkungan yang memiliki komponen-komponen berupa faktor-faktor lingkungan yang berpengaruh terhadap proses implementasi strategi tersebut (Kotler et al, 2003).

1. Product (Produk) merupakan segala sesuatu, baik yang tampak (tangible) seperti lokasi, infrastruktur atau SDM daerah, maupun tidak tampak (intangible) seperti layanan publik dan suprastruktur, yang diciptakan untuk memenuhi kebutuhan dan keinginan konsumen mulai dari awal sampai akhir proses pemasaran. Produk agroindustri di Provinsi Kalimantan Timur seperti pada Tabel 4.

Tabel 4. Produk Agroindustri di Provinsi Kalimantan Timur

\begin{tabular}{cc}
\hline Tangible Product & Intangible Product \\
\hline Pelabuhan KIPI Maloy & One Stop Services \\
Food Estate Delta Kayan &
\end{tabular}

2. Price merupakan nilai produk yang diekspresikan dalam satuan moneter atau nilai tukar uang. Penetapan harga perlu dilakukan secara tepat untuk mencapai tingkat kepuasan konsumen dan memberikan kontribusi keuntungan bagi organisasi. Maksimalisasi keuntungan lebih merupakan kebijakan jangka panjang, sedangkan target return biasanya ditetapkan untuk jangka pendek. 
Tabel 5. Investasi/Biaya Agroindustri di Provinsi Kalimantan Timur

\begin{tabular}{ll}
\hline Produk & Harga/Biaya Yang Harus Dikeluarkan Investor \\
\hline Pelabuhan KIPI Maloy & General Cargo (76,2 Milyar Rupiah) \\
& CPO (883 Milyar Rupiah) \\
& Batubara (3.625,6 Milyar rupiah) \\
& Peti Kemas (1.140,9 milyar Rupiah) \\
Food Estate Delta Kayan & Tanjung Buka 1-2 sepanjang 3 km luas 338 Ha sebesar \\
& $\begin{array}{l}\text { 14 Milyar Rupiah } \\
\text { Tanjung Buka 3-4 sepanjang } 3 \text { km luas } 400 \text { ha sebesar } 14 \\
\text { Milyar Rupiah }\end{array}$ \\
& Tanjung Buka 5-6 sepanjang 3 km luas 300 ha sebesar 14 \\
Milyar Rupiah.
\end{tabular}

Sumber : KP3EI Provinsi Kalimantan Timur (2012)

3. Place merupakan variabel pemasaran yang menentukan saluran pemasaran produk kepada konsumen. Secara umum, saluran pemasaran terdiri atas saluran pemasaran secara langsung oleh organisasi san saluran pemasaran secara tidak langsung melalui pihak lain sebagai perantara dalam suatu sistem saluran pemasaran produk. Untuk kasus agroindustri di Kalimantan Timur, saluran distribusi untuk investasi seperti diperlihatkan pada Gambar 2. Pada Gambar 2, Investor yang akan berinvestasi di bidang agroindustri pada KIPI Maloy ataupun Food Estate Delta Kayan dapat menghubungi BKPM atau langsung datang kepada BPPMD Prov. Kaltim. BPPMD Prov. Kaltim sebagai perwakilan provinsi lalu akan berkoordinasi dengan Pemkab Kutai Timur perihal investasi di KIPI Maloy dan berkoordinasi dengn Pemkab Bulungan perihal investasi di Food Estate Delta Kayan.

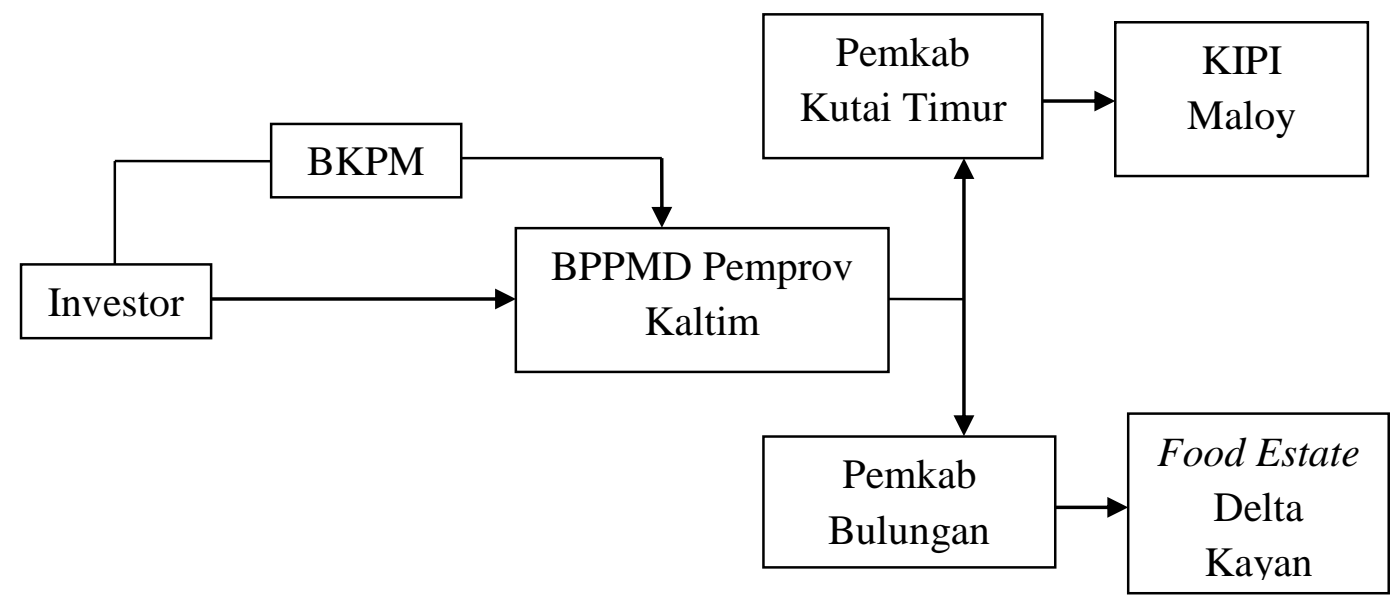

Gambar 3. Saluran Pemasaran Proyek KIPI Maloy dan Food Estate Delta Kayan Di Provinsi Kalimantan Timur Sumber : KP3EI Provinsi Kalimantan Timur (2012)

4. Promotion (promosi) merupakan sarana komunikasi yang digunakan untuk menginformasikan, mempengaruhi, melakukan persuasi, dan mengingatkan konsumen mengenai produk, image, keterlibatan masyarakat, dan dampak sosialnya. Kebijakan promosi berkaitan dengan penentuan materi pesan yang akan dikomunikasikan kepada target audience dengan tujuan mencapai perilaku konsumen seperti yang diinginkan 
organisasi. Kegiatan promosi mengenai kawasan agroindustri di Provinsi Kalimantan Timur dilakukan dengan cara :

a. Mengikuti pameran-pameran internasional seperti Agricultural International Expo (Agrinex Expo), Infrastructure Expo.

b. Menjadi tuan rumah pelaksanaan event nasional dan internasional mengenai agroindustri,

c. Melakukan pemasangan iklan baik cetak maupun media cetak mengenai potensi agroindustri di Kalimantan Timur.

\section{KESIMPULAN}

Untuk menjadikan Provinsi Kalimantan Timur sebagai provinsi agroindustri, semua aspek potensi pemasaran daerah (analisis SWOT, diferensiasi, targeting dan bauran pemasaran) harus dioptimalkan penggunaan karena mereka tidak bisa berdiri sendiri. Daerah tidak dapat hanya mengandalkan keuangannya sendiri untuk mengembangkan daerahnya. Upaya regional harus memiliki kreatif dan inovatif dalam memenuhi peluang bisnis di daerah tersebut. Koordinasi dan integrasi aktivitas promosi merupakan bagian dari konsep pemasaran modern yang saat ini mulai banyak digunakan termasuk program pemasaran daerah. Kecenderungan dalam persaingan antar daerah dalam menarik investasi terutama di sektor agroindustri di Provinsi Kalimantan Timur perlu didukung dengan data dan strategi pengembangan potensi wilayah masing-masing. Pendataan ulang dan strategi pengembangan potensi wilayah sangat diperlukan dalam rangka promosi investasi baik di dalam maupun ke luar negeri.

\section{REKOMENDASI}

Berdasarkan analisis yang dilakukan, maka rekomendasi yang dapat diberikan kepada Pemerintah Provinsi Kalimantan Timur dalam mengembangkan sektor agroindustri adalah sebagai berikut:

1. Membebaskan lahan untuk kegiatan agroindusti;

2. One Stop Services dimana layanan birokrasi dilakukan pada satu tempat;

3. Keterbukaan harga/nilai investasi yang harus dikeluarkan investor;

4. Membangun infrastruktur dasar pada daerah agroindustri;

5. Mengikuti pameran-pameran internasional seperti Agricultural International Expo (Agrinex Expo), Infrastructure Expo;

6. Menjadi tuan rumah pelaksanaan event nasional dan internasional mengenai agroindustri;

7. Melakukan pemasangan iklan baik cetak maupun media cetak mengenai potensi agroindustri di Kalimantan Timur.

\section{DAFTAR PUSTAKA}

Austin, J.E. (1992). Agroindustrial Project Analysis: Critical Design Factors. EDI Series In Economic Development. Baltimore and London: The Johns Hopkins University Press.

BPS Provinsi Kalimantan Timur. (2018), Kalimantan Timur Dalam Angka 2018. Samarinda: BPS Provinsi Kalimantan Timur.

Devaragan. S, Lewis, J.D., dan Robinson. S. (1990). Policy Lessons From Trade-Focussed. Two Sektor Models. Jurnal of Policy Modelling. Vol.12 (4): 625-657.

Kartajaya, Hermawan dan Yuswohady (2005). Attracting Tourists, Traders, Investors: Strategi Memasarkan Daerah. Jakarta: Penerbit Gramedia. 
Kementerian Perindustrian Republik Indonesia (2011), Outlook Industri 2012: Strategi Percepatan dan Perluasan Agroindustri. Jakarta, Indonesia.

Kotler, Philip, Haider, D.H \& Rein, I. (1993), Marketing Places. New York: The Free Press.

Kotler, Philip (2002), Marketing Management, $11^{\text {th }}$ Edition. New Jersey: Prentice Hall, Inc.

Kotler, Philip, Michael A. Hamlin, Irving Rein \& Donald H. Haider (2003). Marketing Asian Places : Attracting Investment, Industry, and Tourism to Cities, States, and Nations. Singapore: John Wiley \& Sons, Inc

Kotler, Philip \& Lee, Nancy (2007). Marketing In The Public Sector: A Roadmap For Improved Performance. New Jersey: Wharton School Publishing.

KP3EI Provinsi Kalimantan Timur (2012). Progres Proyek MP3EI di Provinsi Kalimantan Timur. Samarinda, Indonesia.

Quinn, James Brian. (1980). Strategies for change: Logical incrementalism. Homewood, Ill: R.D. Irwin. 